\title{
Article \\ Bismuth Oxyhalides for NOx Degradation under Visible Light: The Role of the Chloride Precursor
}

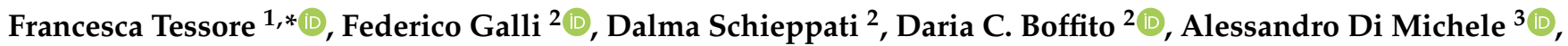 \\ Francesco Demartin ${ }^{1}(\mathbb{D})$, Giuseppina Cerrato ${ }^{4, *}$ and Claudia L. Bianchi ${ }^{1}$ (D) \\ 1 Dipartimento di Chimica, Università degli Studi di Milano, Via Golgi 19, 20133 Milano, Italy; \\ francesco.demartin@unimi.it (F.D.); claudia.bianchi@unimi.it (C.L.B.) \\ 2 Chemical Engineering Department, Polytechnique Montréal, C.P. 6079, Succ. Centre-Ville, \\ Montréal, QC H3C 3A7, Canada; federico.galli@polymtl.ca (F.G.); dalma.schieppati@polymtl.ca (D.S.); \\ daria-camilla.boffito@polymtl.ca (D.C.B.) \\ 3 Dipartimento di Fisica e Geologia, Università degli Studi di Perugia, Via Pascoli, 06123 Perugia, Italy; \\ alessandro.dimichele@collaboratori.unipg.it \\ 4 Dipartimento di Chimica, Università degli Studi di Torino, Via Pietro Giuria 7, 10125 Torino, Italy \\ * Correspondence: francesca.tessore@unimi.it (F.T.); giuseppina.cerrato@unito.it (G.C.)
}

Citation: Tessore, F.; Galli, F.; Schieppati, D.; Boffito, D.C.; Di Michele, A.; Demartin, F.; Cerrato, G.; Bianchi, C.L. Bismuth Oxyhalides for NOx Degradation under Visible Light: The Role of the Chloride Precursor. Catalysts 2021, 11, 81. https://doi.org/10.3390/catal11010081

Received: 19 December 2020

Accepted: 4 January 2021

Published: 8 January 2021

Publisher's Note: MDPI stays neutral with regard to jurisdictional clai$\mathrm{ms}$ in published maps and institutional affiliations.

Copyright: $(2021$ by the authors. Licensee MDPI, Basel, Switzerland. This article is an open access article distributed under the terms and conditions of the Creative Commons Attribution (CC BY) license (https:// creativecommons.org/licenses/by/ $4.0 /)$.

\begin{abstract}
Photocatalysis is a green technology for tackling water and air contamination. A valid alternative to the most exploited photocatalytic material, $\mathrm{TiO}_{2}$, is bismuth oxyhalides, which feature a wider bandgap energy range and use visible radiation to attain photoexcitation. Moreover, their layered structure favors the separation of photogenerated electron-hole pairs, with an enhancement in photocatalytic activity. Controlled doping of bismuth oxyhalides with metallic bismuth nanoparticles allows for further boosting of the performance of the material. In the present work, we synthesized Y\%Bi-doped $\mathrm{BiO}\left(\mathrm{Cl}_{0.875} \mathrm{Br}_{0.125}\right)(\mathrm{Y}=0.85,1,2,10)$ photocatalysts, using cetyltrimethylammonium bromide as the bromide source and varying the chloride source to assess the impact that both length and branching of the hydrocarbon chain might have on the framing and layering of the material. A change in the amount of the reducing agent $\mathrm{NaBH}_{4}$ allowed tuning of the percentage of metallic bismuth. After a thorough characterization (XRPD, SEM, TEM, UV-DRS, XPS), the photocatalytic activity of the catalysts was tested in the degradation of NOx under visible light, reaching a remarkable $53 \%$ conversion after $3 \mathrm{~h}$ of illumination for the material prepared using cetylpyridinium chloride.
\end{abstract}

Keywords: photocatalysis; NOx degradation; bismuth oxyhalides; cetylpyridinium chloride; cetyltrimethylammonium bromide

\section{Introduction}

Water and air pollution has become a worldwide concern as it affects humans, flora, and fauna. Air pollution kills about 3 million people a year [1]. Water pollution accounts for unknown long- and short-term effects on both aquatic life and human health [2] and restricted access to safe water causes more than 1.6 million deaths annually [3].

In the last 20 years, photocatalysis has been applied to a wide variety of fields, from the environment [4-6], to the building industry [7], and energy-related areas [8] to biomedical specialties. The absorption of a photon of proper energy by a semiconductor promotes an electron from the valence band to the conduction band, which in turn creates an electron vacancy (hole) in the valence band. The electron-hole pairs can either recombine or take part in a chemical reaction that involves surface-adsorbed species.

Photocatalysis has proven to be a valid technology for tackling water and air contamination [9]. Indeed, it is adequate for air purification, especially in indoor environments, as the concentration of pollutants is low and no saturation of the surface of photocatalysts can occur. 
Because of its optimal physicochemical properties, titanium dioxide $\left(\mathrm{TiO}_{2}\right)$ is the most exploited photocatalytic material in almost every field of application. It is chemically stable, nontoxic, and cheap. In particular, Degussa P25 features great performance in both aqueous [10,11] and air environments [12]. However, its nanometric particle size limits its application as it poses serious threats when it comes to dermal and pulmonary exposure [13]. Moreover, pollutant conversion kinetics by $\mathrm{TiO}_{2}$ is not fast enough to comply with environmental needs. Bianchi et al., for instance, reported total elimination of ethanol and acetaldehyde in $60 \mathrm{~min}$ [14].

In fact, $\mathrm{TiO}_{2}$ has wide bandgap energy $(3.2 \mathrm{eV}$ for the anatase phase and $3.0 \mathrm{eV}$ for the rutile phase) [15] and it is active only in the ultraviolet region [16], which is less than $10 \%$ of the overall solar radiation. $\mathrm{TiO}_{2}$ doped with silver species exhibits tiny to significant increases in photocatalytic activity if, for instance, we consider acetone abatement, as reported by Stucchi et al. [9]: they observed a 3-11\% increase after $6 \mathrm{~h}$ of reaction and $24 \%$ of acetone converted into oxidized products.

A valid alternative to $\mathrm{TiO}_{2}$ is represented by bismuth oxides, which feature a wider bandgap energy range and use visible radiation to attain photoexcitation.

Specifically, bismuth oxyhalides ( $\mathrm{BiOX}$, with $\mathrm{X}=\mathrm{F}, \mathrm{Cl}, \mathrm{Br}$, I) exhibit a layered structure wherein halides line up between $\left[\mathrm{Bi}_{2} \mathrm{O}_{2}\right]$ layers. This arrangement elicits the formation of an internal electric field between positive $\left[\mathrm{Bi}_{2} \mathrm{O}_{2}\right]^{2+}$ layers and the negative halogen ones [17]. This induces a beneficial separation of the photogenerated electron-hole pairs, thus enhancing the photocatalytic activity of the material [18].

Wang et al. synthetized xBiOI- $(1-x) \operatorname{BiOCl}[17]$ and $x \operatorname{BiOBr}-(1-x) B i O I ~[19]$ catalysts with high photocatalytic activity under visible light for the degradation of methyl orange (MO), reaching a $92 \%$ degree of photodegradation of MO after $5 \mathrm{~h}$ of reaction with $\mathrm{BiOBr}_{0.75} \mathrm{I}_{0.25}$.

Sasson et al. reported the synthesis of several $\mathrm{BiO}\left(\mathrm{Cl}_{x} \mathrm{Br}_{1-\mathrm{x}}\right)$ photocatalysts by hydrothermal method using hydrohalic acids and they proved excellent activity for Rhodamine $B$ and Acetophenone degradation in an aqueous environment [20].

They also optimized the synthetic protocol for the preparation of $\mathrm{BiO}\left(\mathrm{Cl}_{\mathrm{x}} \mathrm{Br}_{1-\mathrm{x}}\right)$ through the use of quaternary ammonium salts, namely cetyltrimethylammonium chloride (CTAC) and bromide (CTAB) (Figure 1), in acidic aqueous conditions at room temperature, to create 3D flowerlike nanostructures with enhanced activity under visible radiation [21]. A controlled doping of these mixed oxyhalides with metallic bismuth nanoparticles allowed novel $Y \%$ Bi-doped $\mathrm{BiOCl}_{\mathrm{x}} \mathrm{Br}_{1-\mathrm{x}}$ heterojunction solid solutions to be obtained with a more effective electron-hole pair separation, further boosting the photocatalytic performances towards degradation of common organic pollutants in water under visible light illumination [22] or solar irradiation [23].

Bismuth halides and metal bismuth are reported to be very effective towards the photodegradation of NOx, which the World Health Organization (WHO) ranks among the major air pollutants [24].

Metallic bismuth showed itself in plasmonic photocatalysis. Under $280 \mathrm{~nm}$ light radiation, $0.1 \mathrm{~g}$ of $100 \mathrm{~nm}$ Bi nanoparticles oxidized 45\% NO (initial concentration of $600 \mathrm{ppb}$ ) [25]. Metallic bismuth also activates amorphous bismuth oxide under visible light: $15 \mathrm{~mL} \mathrm{~min}^{-1}$ of a NO stream (550 ppb) was oxidized with 55\% conversion [26].

Zhang et al. degraded $\mathrm{NO}$ with bismuth oxyhalides (with $\mathrm{Cl}, \mathrm{Br}$, and I) [27]. Their bandgap and thermal stability decrease with the increase in atomic number of the halide. $\mathrm{BiOBr}$ showed higher oxidative power for $\mathrm{NO}_{2}$ than $\mathrm{BiOCl}$ and $\mathrm{BiOI}$, with an exit-to-feed removal rate of $21 \%$.

In the present work, we synthesized $\mathrm{Y} \% \mathrm{Bi}$-doped $\mathrm{BiO}\left(\mathrm{Cl}_{0.875} \mathrm{Br}_{0.125}\right)(\mathrm{Y}=0.85,1,2,10)$ photocatalysts, setting CTAB as the main bromide source, since $\mathrm{BiOBr}$ species have been reported to be more photocatalytically active than bare $\mathrm{TiO}_{2}[19]$ and more active than other oxyhalides [27]. Instead, we varied the chloride source (dodecyltrimethylammonium chloride (DTAC), cetyltrimethylammonium chloride (CTAC), cetylpyridinium chloride (CPC) and benzyltrimethylammonium chloride (BTAC), see Figure 1) to assess the effect 
that both the length and branching of the hydrocarbon chain may elicit on (i) framing and layering of the material and (ii) the final photocatalytic activity.

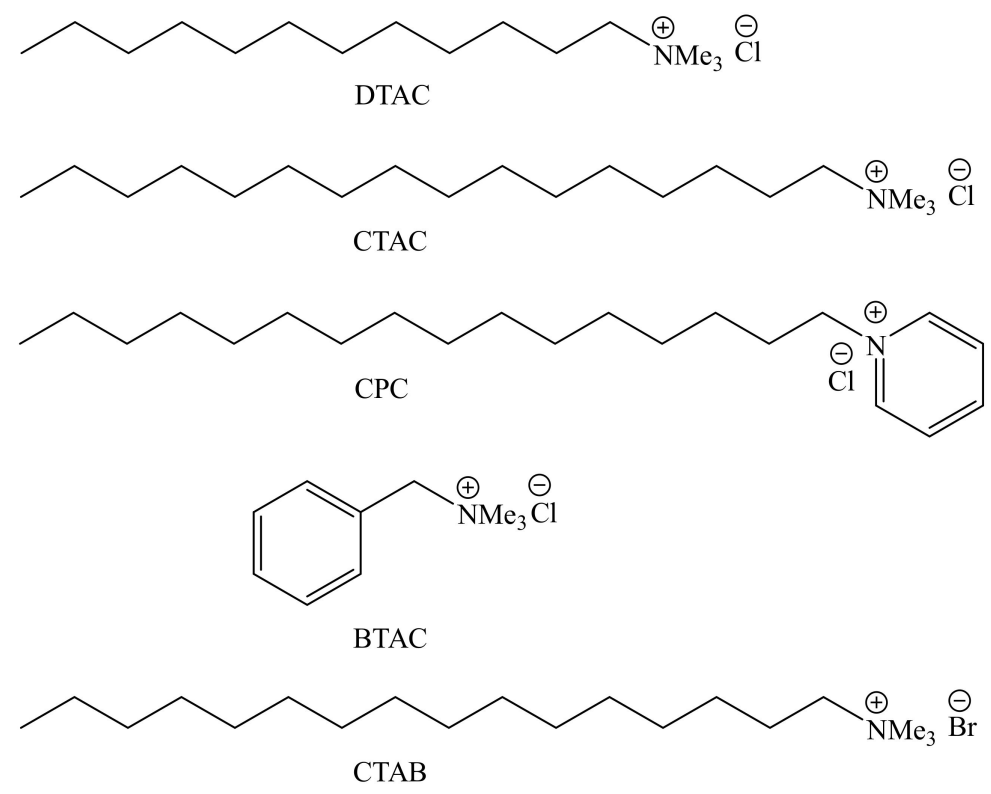

Figure 1. Chloride and bromide sources considered in the present work.

A synopsis of all the investigated photocatalysts is reported in Table 1.

Table 1. Synopsis of the $\mathrm{Y} \% \mathrm{Bi}$-doped $\mathrm{BiO}\left(\mathrm{Cl}_{0.875} \mathrm{Br}_{0.125}\right)$ photocatalysts studied in this work.

\begin{tabular}{ccc}
\hline Sample & Chloride Source & Nominal Percentage of Metallic Bi \\
\hline 1 & DTAC & 0.85 \\
2 & CPC & 0.85 \\
3 & CTAC & 1.0 \\
4 & CPC & 1.2 \\
5 & BTAC & 1.1 \\
6 & CTAC 25\% water & 1.2 \\
7 & CPC & 2.0 \\
8 & CPC & 10 \\
\hline
\end{tabular}

The choice of the $\mathrm{Cl} / \mathrm{Br}$ ratio was due to the exceptional photocatalytic performances reported for the $\mathrm{BiO}\left(\mathrm{Cl}_{0.875} \mathrm{Br}_{0.125}\right)$ composite, capable of completely abating $15 \mathrm{mg} \mathrm{L}^{-1}$ of Rhodamine $\mathrm{B}$ aqueous solution in $120 \mathrm{~s}$ under visible light irradiation [21].

Moreover, by tuning the amount of the reducing agent, $\mathrm{NaBH}_{4}$, we partially reduced the amount of $\mathrm{Bi}^{3+}$ species present on the catalyst to metallic $\mathrm{Bi}$ to exploit its plasmonic band to increase the photocatalytic effect.

Since the main participant of ambient pollution is ozone, as it forms through the photochemical oxidation of volatile organic compounds (VOCs) and carbon monoxide (CO) in the presence of nitrogen oxides (NOx) [28], we investigated the activity of our catalysts by degrading NOx under visible light, reaching a remarkable $53 \%$ conversion after $3 \mathrm{~h}$ of illumination for the catalyst prepared using CPC. Indeed, to the best of our knowledge, no data for these catalysts are available for the gas phase degradation of NOx.

\section{Results and Discussion}

\subsection{XRPD and SEM}

All the XRPD patterns (Figures S1-S8 in the Supplementary Materials) can be indexed according to the tetragonal $\mathrm{P} 4 / \mathrm{nmm}$ space group of the BiOX phases and are similar to those of the $\mathrm{BiOCl}_{x} \mathrm{Br}_{(1-x)}$ family, with the same broadening of the peaks observed by other 
authors [21,22]. We did not identify the characteristic peaks of the $\mathrm{Bi}^{0}$ particles probably because of their low content and high dispersion. We can safely assume that $\mathrm{Bi}^{0}$ particles are deposited only on the surface [22].

The relative intensity of the peaks in the $\mathrm{BiOCl}_{\mathrm{x}} \mathrm{Br}_{(1-\mathrm{x})}$ patterns is affected by the morphology of the composite catalyst. In particular, samples 4,7 , and 8 show an increase in intensity of the (001) reflection at $2 \theta \sim 12^{\circ}$, which is the most intense reflection in the pattern, due to the preferred orientation of the catalyst particles along that direction.

This feature matches the SEM observations (Figure 2), which evidenced 2D-lamellar aggregates for the same samples, similar to the ones obtained starting from ammonium chloride as the $\mathrm{Cl}$ precursor and $\mathrm{Bi}\left(\mathrm{NO}_{3}\right)_{3}[29,30]$.
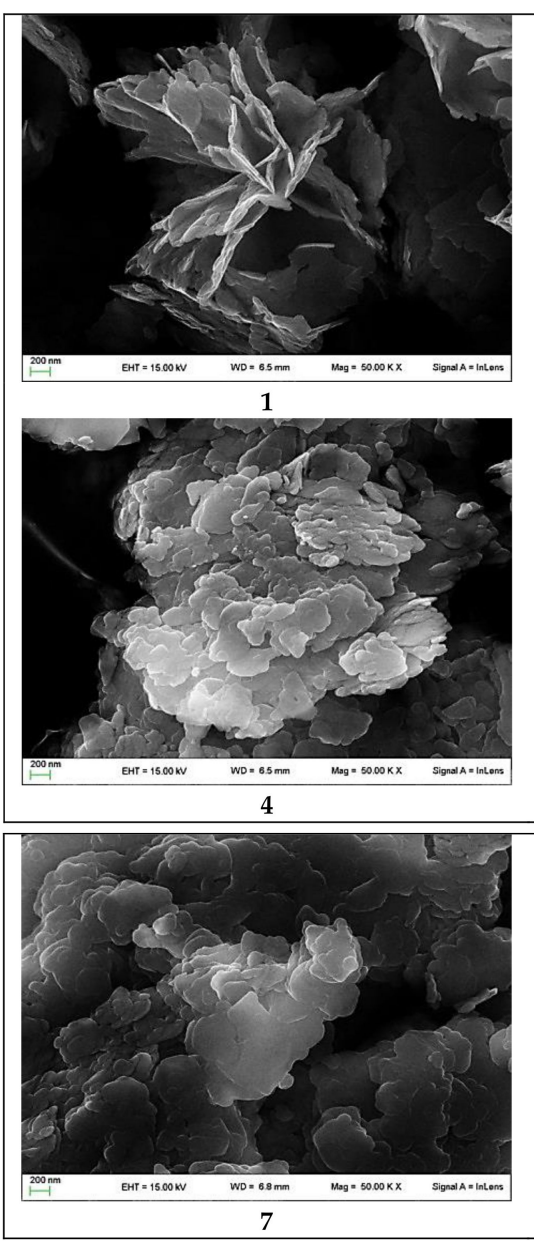
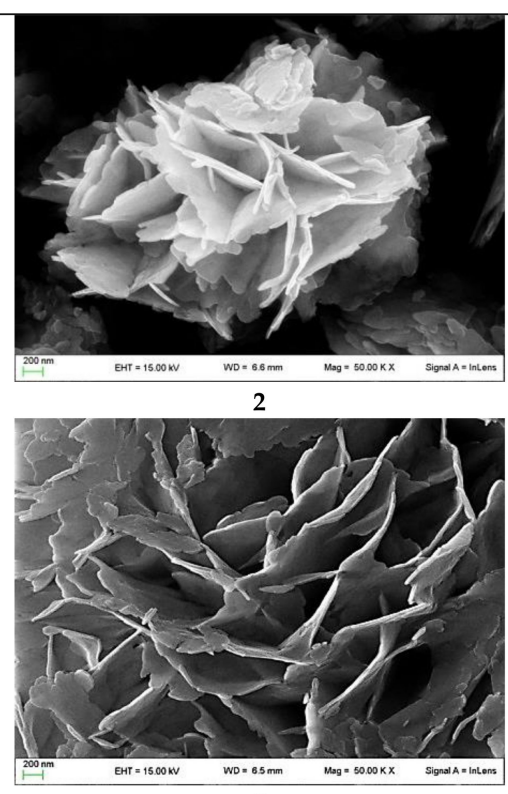

5
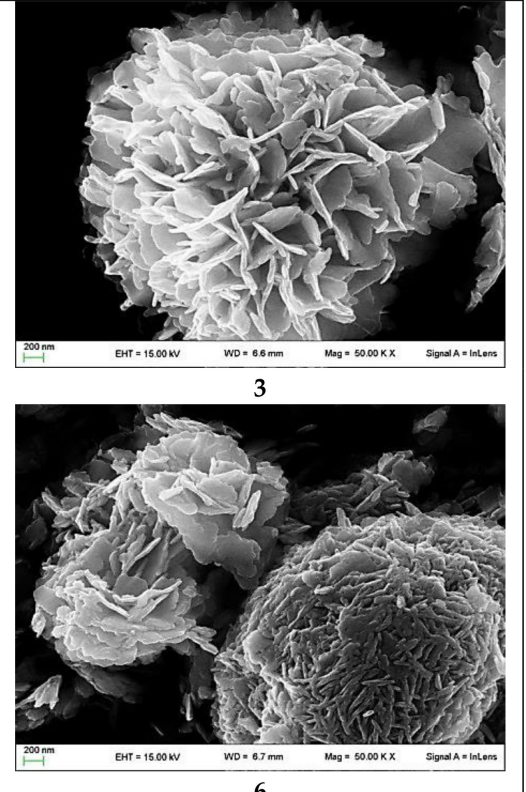

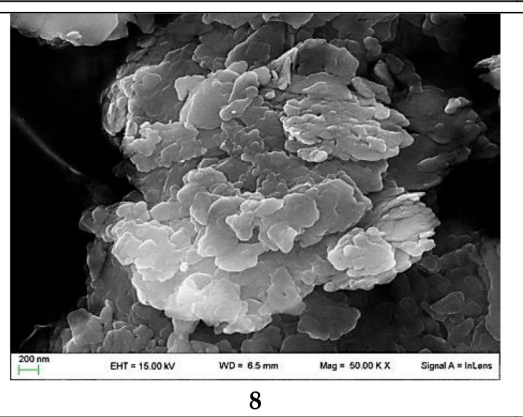

Figure 2. FE-SEM images of samples 1-8 at Mag $50.00 \mathrm{KX}$.

On the other hand, the preferential orientation, and consequently, the (001) reflection, are less intense for samples 1,2,3, and 6, which, accordingly, exhibit a spherical flowerlike 3D morphology.

Sample 5 appears as an exception, since it presents an intense (001) reflection in the XRPD pattern, but an undefined morphology, more similar to a flowerlike aggregate, even if TEM analysis also evidences the presence of lamellar aggregates. However, its crystallinity is low (see Figure S5), which presumably is the origin of this anomaly.

We can tentatively correlate the XRPD patterns and SEM observations with both the nature of the chloride precursor and the amount of $\mathrm{NaBH}_{4}$ added. Indeed, trimethylammonium salts, such as DTAC, CTAC, and BTAC, produce flowerlike aggregates, with apparently no perceivable effect of the length of the alkyl chain and of the amount of $\mathrm{NaBH}_{4}$ added. On the other hand, the more sterically hindered pyridinium derivative CPC leads to sheet-like morphologies. Moreover, we also observe an effect of the amount of 
$\mathrm{NaBH}_{4}$, since an enhancement of the latter from 0.85 eq. (sample 2) to 1.2-10 eq. (samples 4, 7 , and 8) seems to favor a lamellar morphology.

Therefore, we conclude that both the nature of the reagents providing the chloride for the composite catalyst and the amount of $\mathrm{NaBH}_{4}$ added are critical for determining the final morphology of the composite.

Shenawi-Khalil et al., to verify Vegard's law for the $\mathrm{BiOCl}_{\mathrm{x}} \mathrm{Br}_{(1-\mathrm{x})}$ solid solutions, derived the following linear relation between the unit-cell $c$ parameter and the $\mathrm{Cl} / \mathrm{Br}$ ratio: $c=8.099-0.7386 x$ [20]. The composition computed using the values of unit cell $c$ parameter for all our prepared samples gave $x$ values in the $0.83-0.90$ range, with the only exception of sample 7 , which gave $x=0.98$.

\subsection{HRTEM}

As for the investigation carried out by means of HRTEM, all the samples that were investigated exhibit variable morphological features, ranging from extended thin layers with no defined contours to aggregates of small particles with more roundish contours (see Figure 3). Occasionally, it is possible to observe the presence of crystallinity, witnessed by large patches of fringe patterns.

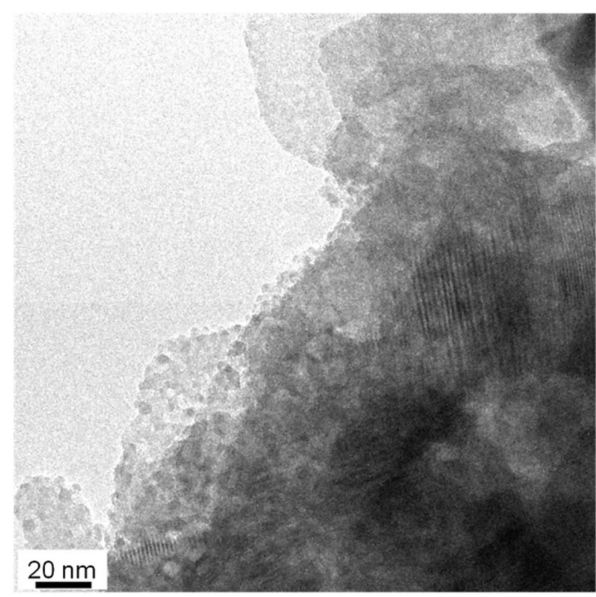

Figure 3. TEM image at medium magnification of sample 1.

If the investigation is carried out at higher magnification, again for all the samples, similar features are present (see Figure 4), even though for sample 5 (Figure S11 in the Supplementary Materials) it was hard to identify nanoparticles highly interacting with one another: the material is mainly composed of lamellar aggregates, confirming the FE-SEM results.
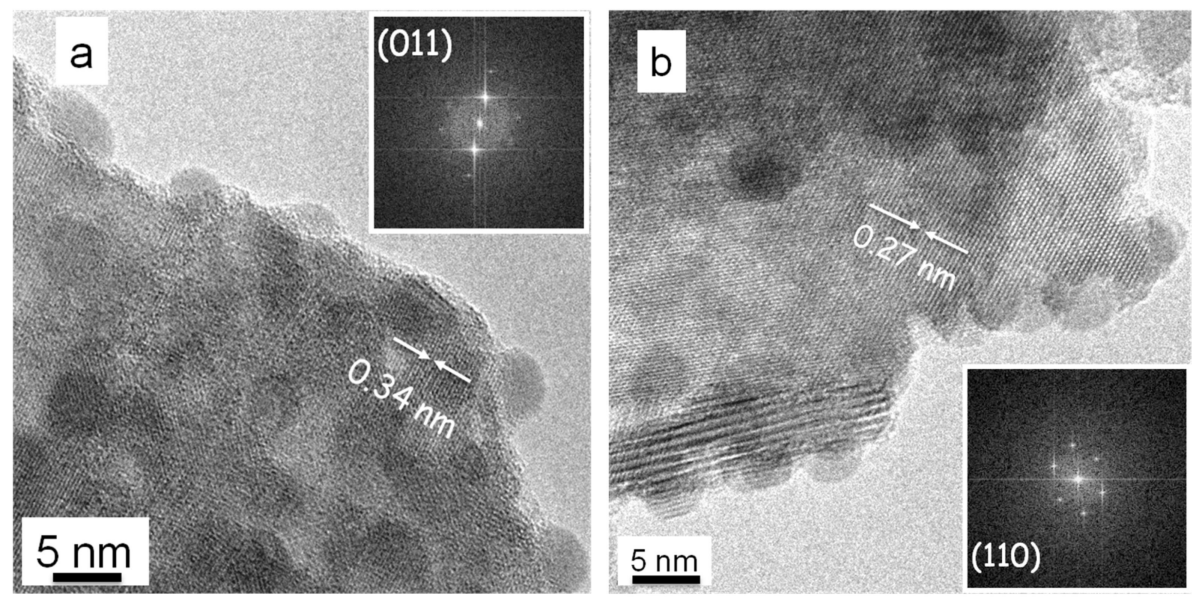

Figure 4. HRTEM images at high magnification of (a) sample 1 and (b) sample 2. 
Both $\mathrm{d}(\mathrm{hkl})=(011)$ with distances of ca. $0.34 \mathrm{~nm}$ and $\mathrm{d}(\mathrm{hkl})=(110)$ with distances of ca. $0.27 \mathrm{~nm}$ (similar to the one measured by Yan et al. on pristine BiOCl nanoplates [30]) are observed as major components of bismuth oxide chloride (bismoclite) (see ICDD card n. 01-073-2060). The high crystalline nature of the samples is also witnessed by the FFT analyses of the direct images, obtaining in all cases diffraction patterns confirming the assignments to the above families of crystal planes. The presence of black fringes in the bottom-left part of Figure $4 \mathrm{~b}$ ascribes to the thickness or Moiré's fringes generated by the superimposition of crystalline particles with similar fringe patterns.

\section{3. $D R S$}

The UV-vis DRS spectra of the photocatalysts (Figure S9 in Supplementary Materials) show an intense absorption centered in the ultraviolet region (220-390 nm), and are comparable regardless of the chloride source involved in the synthesis, with the only exception of sample 7, which presents a broader band extending through the visible.

The Kubelka-Munk model [31] allowed the determination of the bandgap of the photocatalysts through a Tauc plot [32]. The values of $(A h v)^{1 / 2}$ were plotted versus photoenergy (Figure S10 in Supplementary Materials), estimating bandgaps ( $\left.E_{g}\right)$ from the intercept of the tangent to the plots (Table 2) [27].

Table 2. Synopsis of XPS, bandgap, and catalytic activity for samples 1-8. For the atomic surface, the remaining component is oxygen.

\begin{tabular}{ccccccc}
\hline Sample & Chloride Source & Bi Atomic $\%$ & $\mathbf{\%} \mathbf{B r}$ & $\mathbf{\%} \mathbf{C l}$ & $\mathbf{E}_{\mathbf{g}}(\mathbf{e V})$ & $\begin{array}{c}\text { NOx Conv } \\
(\mathbf{t}=\mathbf{3} \mathbf{h})\end{array}$ \\
\hline 1 & DTAC & 6 & 5 & 29 & 3.03 & 17 \\
2 & CPC & 22 & 6 & 25 & 2.98 & 53 \\
3 & CTAC & 7.5 & 3 & 15 & 3.01 & 34 \\
4 & CPC & 5.7 & 4 & 16 & 2.95 & 13 \\
5 & BTAC & 6.9 & 4 & 23 & 3.05 & 11 \\
6 & CTAC 25\% water & 30 & 2 & 13 & 3.07 & 12 \\
7 & CPC & 5.4 & 2 & 15 & 2.81 & 20 \\
8 & CPC & 4.6 & 3 & 15 & 3.00 & 17 \\
\hline
\end{tabular}

The bandgaps are in the range $2.81-3.07 \mathrm{eV}$, in reasonable agreement with the values reported for pure $\mathrm{BiOBr}$ and $\mathrm{BiOCl}$ (2.76 and $3.20 \mathrm{eV}$, respectively) [27].

\subsection{XPS}

XPS analysis allowed us to ascertain the amount of metallic bismuth on the surface of our samples. We analyzed the $\mathrm{BiO} 4 \mathrm{f} 7 / 2$ and $4 \mathrm{f} 5 / 2$ peaks and deconvoluted them, considering a slit of $5.31 \mathrm{eV}$ and $\mathrm{Bi}^{0}$ peaks to be at 156.9 and $162.3 \mathrm{eV}$, and calculating the area ratio between $\mathrm{Bi}^{0}$ and $\mathrm{Bi}^{3+}$ peaks (Figure 5).

While the amount of $\mathrm{Bi}^{0}$ on the surface of all the samples is in the range 4.6-7.5\%, for samples 2 and 6, a higher percentage (22\% and 30\%, respectively) was found (Table 2). For sample 6, this might be due to the different preparation, since the chloride precursor was added to the reaction mixture using a $25 \% \mathrm{wt}$. aqueous solution of CTAC, instead of the solid surfactant as in the other syntheses.

On the other hand, the $22 \%$ metallic bismuth found for sample 2 is quite surprising, but nicely correlates with its enhanced ability to convert NOx.

The $\mathrm{Br}$ atomic percentage in the surface of all samples is between 2 and $6 \%$. On the other hand, the $\mathrm{Cl}$ atomic percentage varies between $13 \%$ and $29 \%$ (Table 2). 


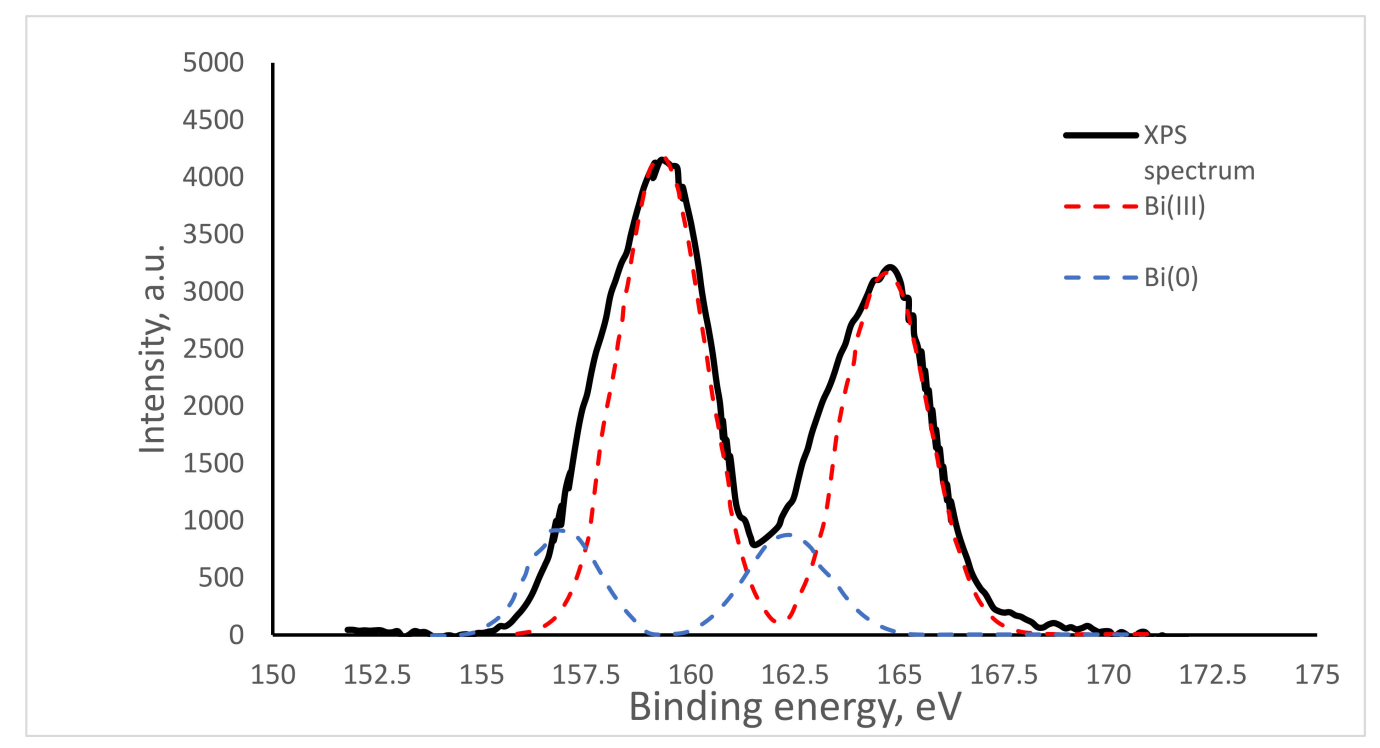

Figure 5. XPS spectrum of sample 2.

\subsection{Catalytic Tests}

Most samples converted a maximum of $20 \%$ NOx in $3 \mathrm{~h}$ : this result is comparable to the result obtained with the micrometric anatase/rutile heterojunction (Kronos 1077) [33]. Sample 2 exceptionally converted 53\% of NOx (see Figure 6). Li et al. tested bismuth oxide for the same reaction, employing an LED light with 10 times higher power (150 vs. $16.8 \mathrm{~W}$ in this work). In addition, the NO concentration they employed was about 10 times the one of this work [26]. In another work, Wang et al. obtained a fast NO oxidation using a $150 \mathrm{~W}$ lamp and a continuous reactor configuration, reaching a peak oxidation of $35 \%$ after $5 \mathrm{~min}$, which decreased because of $\mathrm{NOx}^{-}$deposition on the catalyst's active sites [34], a phenomenon that we also observed in the long-run NOx photodegradation reaction [5]. Considering pseudo-first order kinetics and a direct proportion between the rate constant and the LED power applied (which is valid in the case of NOx degradation, as we obtained the same dependence in another research [5]), sample 2 results 4 times faster compared to bismuth oxide for this reaction under LED light (rate constant of 0.07 versus $0.02 \mathrm{~h}^{-1} \mathrm{~g}^{-1} \mathrm{~cm}^{-2} \mathrm{~W}^{-1}$ ). Compared with bismuth oxyhalides nanolayers, our catalysts showed lower performances [27]. However, the nanoplates deactivated because of $\mathrm{NO}_{3}{ }^{-}$deposition on their surface, resulting in a very low catalyst stability (less than $5 \mathrm{~min}$ ) [27]. Moreover, the dimension of the particles in the nanometric range poses health concerns. Sample 2 shows similar performances to Ag nanoparticles-doped micrometric titania [34] prepared in basic conditions with a PVP/Ag molar ratio of 1 or 50, but the reaction kinetics are not comparable with the sample prepared with a PVP/Ag molar ratio of 3 [34]. Further improvements are necessary to enhance the reaction kinetics of the bismuth oxyhalides, which however remain a component with no nanoparticles deposited on them, i.e., intrinsically safer for health. Gnayem et al. studied the photodegradation of various recalcitrant organic contaminants in the aqueous phase and concluded that bismuth oxyhalides are stable after many catalytic cycles [22]. Considering that (1) we studied a gas phase reaction, characterized by lower mechanical attrition on the catalyst's surface due to no stirring and lower medium viscosity and (2) we employed lower energy (LED) light compared to UV, we assume that catalysts are stable at the operative conditions. 


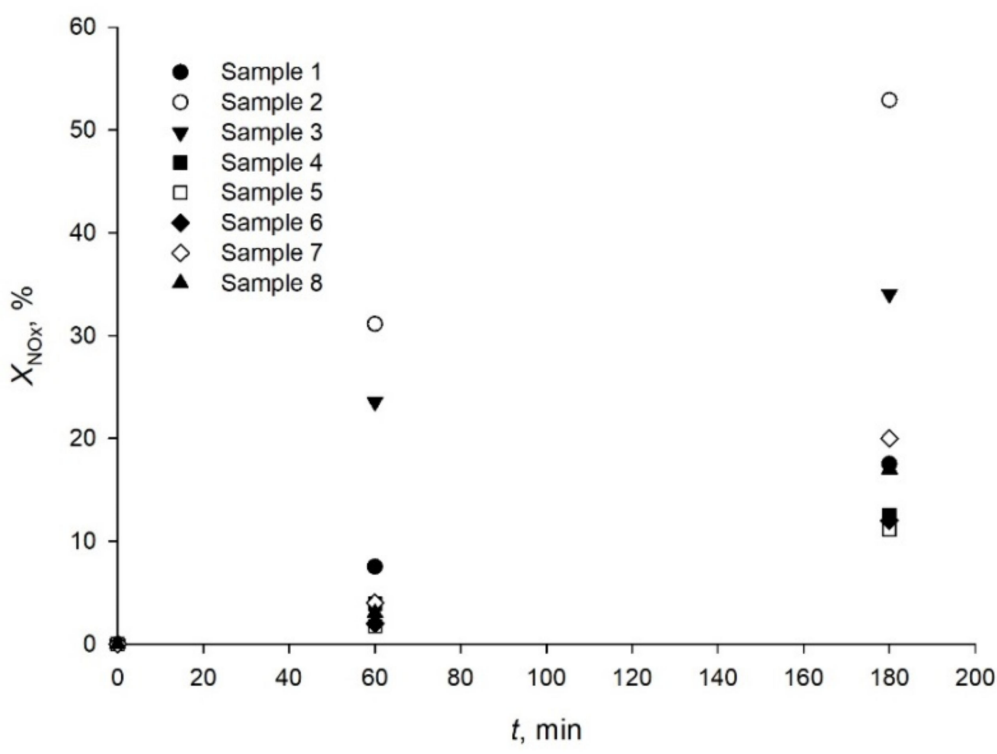

Figure 6. NOx degradation for sample 1-8 versus time.

Concerning the photodegradation of the NOx mechanism, we speculate that it proceeds through the adsorption of $\mathrm{NO}$ on the surface of the catalyst, followed by its reduction to $\mathrm{N}_{2} \mathrm{O}$ by the electrons photopromoted to the valence band of our catalysts. Eventually, $\mathrm{N}_{2} \mathrm{O}$ decomposes to dinitrogen, while the oxygen reacts to another adsorbed oxygen to give dioxygen. $\mathrm{Xu}$ et al. proposed the same mechanism for Ag-doped $\mathrm{TiO}_{2}$ [35]. However, we refrain from speculating on the electron-hole pair formation mechanism (plasmonic resonance of $\mathrm{Bi}(0)$, heterojunction created by $\mathrm{Bi}$ oxyhalides, or main bandgap promotion) since we do not possess enough information to make such a claim.

The content of metallic bismuth on the surface correlates with the final NOx conversion $\left(R^{2}=0.53\right.$, see Figure 7) except for sample 6 , which was prepared starting from an aqueous solution of the chloride precursors, instead of adding the surfactant directly to the reaction mixture. The same trend was reported for the liquid phase discoloration of $\mathrm{RhB}$ solution [30].

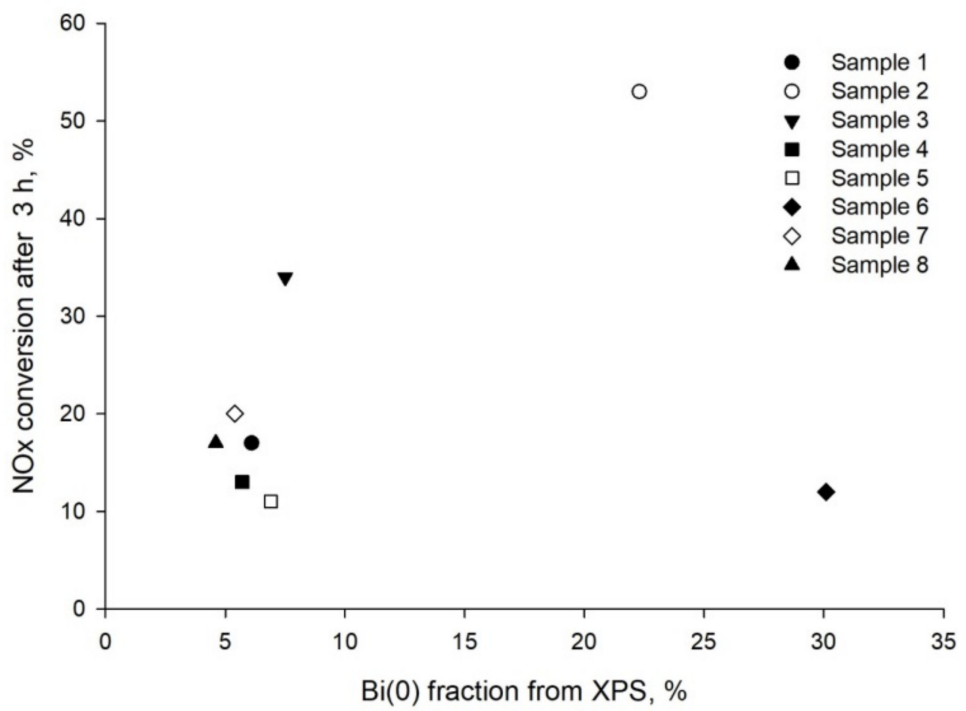

Figure 7. NOx degradation as a function of metallic bismuth on the surface. 


\section{Materials and Methods}

\subsection{Synthesis}

All the reagents were purchased by Merck KGaA (Darmstadt, Germany).

The synthesis of $\mathrm{Y} \% \mathrm{Bi}$-doped $\mathrm{BiO}\left(\mathrm{Cl}_{0.87} \mathrm{Br}_{0.13}\right)(\mathrm{Y}=0.85,1,2,10$; Table 1) was achieved through the reported protocol [22]. In the typical procedure, we placed ground $\mathrm{Bi}\left(\mathrm{NO}_{3}\right)_{3} \cdot 5 \mathrm{H}_{2} \mathrm{O}$ into a $50 \mathrm{~mL}$ round-bottom flask. We added deionized water $(7 \mathrm{~mL})$ and glacial acetic acid $(4 \mathrm{~mL})$. The mixture was stirred for $30 \mathrm{~min}$ at room temperature until a clear and transparent solution formed.

In the meantime, we prepared a second solution in a $100 \mathrm{~mL}$ round-bottom flask by dissolving CTAB (0.125 eq.) and the selected chloride precursor ( 0.875 eq.) in deionized water $(10 \mathrm{~mL})$.

We then dropped the $\mathrm{Bi}\left(\mathrm{NO}_{3}\right)_{3} \cdot 5 \mathrm{H}_{2} \mathrm{O}$ solution into the surfactant solution in $30 \mathrm{~min}$ under vigorous stirring. Eventually, we added variable amounts of $\mathrm{NaBH}_{4}(0.85-10$ eq. with respect to $\left.\mathrm{Bi}\left(\mathrm{NO}_{3}\right)_{3} \cdot 5 \mathrm{H}_{2} \mathrm{O}\right)$ to reduce $\mathrm{Bi}^{3+}$ to $\mathrm{Bi}^{0}$. After $1 \mathrm{~h}$ of vigorous stirring at room temperature, we recovered the precipitate upon filtration and washed it with EtOH $(2 \times 5 \mathrm{~mL})$ and deionized water $(2 \times 20 \mathrm{~mL})$. It was then dried overnight at room temperature. The final product was a white powder.

\subsection{Characterization}

\subsubsection{X-ray Powder Diffraction}

A Philips PW3020 diffractometer (Philips, Eindhoven, The Netherlands) with a $0.25^{\circ}$ divergence slit, 0.04 rad soller slits, and a $0.2 \mathrm{~mm}$ receiving slit determined the crystallinity of our samples. The source of X-ray radiation was a graphite monochromated $\mathrm{CuK} \alpha$ radiation $(\lambda=0.15418 \mathrm{~nm}$ ) with the following measurement conditions: tube voltage of $40 \mathrm{kV}$, tube current of $40 \mathrm{~mA}$, step scan mode with a step size of $0.02^{\circ}$, and counting time of 1 s per step.

A background quartz sample held the sample. The instrument recorded the diffraction pattern between $10^{\circ}$ and $70^{\circ}$ at room temperature.

\subsubsection{Scanning Electron Microscopy and Transmission Electron Microscopy}

A Field Emission Electron Scanning Microscope (FE-SEM) LEO 1525 ZEISS (Jena, Germany) determined the samples' morphology. The samples were deposited on conductive carbon adhesive tape and metalized with chromium.

A high-resolution transmission electron microscope (HR-TEM JEOL 3010-UHR, Tokyo, Japan) inspected the micro- and nanostructure of all the samples (acceleration potential: $300 \mathrm{kV}$; LaB 6 filament). Samples were dry dispersed on $\mathrm{Cu}$ grids covered with Lacey carbon $\mathrm{Cu}$ grids.

\subsubsection{UV-vis Diffuse Reflectance Spectroscopy}

A double beam UV-vis-NIR scanning spectrophotometer (Shimadzu UV-3600 plus, Tokyo, Japan) equipped with a diffuse reflectance accessory (integrating sphere from BIS603) recorded the diffuse reflectance spectra (DRS) of the photocatalysts in the wavelength range 220-2600 $\mathrm{nm}$. The finely ground powder sample was uniformly pressed in a circular disk (with an external diameter of $0.5 \mathrm{~cm}$ ) included in the sample holder; the latter was inserted in a special quartz cuvette and then fixed on a window of the integrating sphere for the reflectance measurements. $\mathrm{BaSO}_{4}$ was the reflectance reference compound.

\subsubsection{X-ray Photoelectron Spectroscopy}

An M-probe apparatus (XPS -M-Probe, Surface Science Instruments, Mountainview, CA, USA) recorded the XPS spectra. The instrument is equipped with a monochromatic $\mathrm{Al}_{\mathrm{k} \alpha}$ anode and is calibrated using $\mathrm{C} 1 \mathrm{~s}$ peak at $284.6 \mathrm{eV}$. 


\subsubsection{Photocatalytic Tests}

To prepare the sample, we suspended $50 \mathrm{mg}$ of ground powder in a beaker with $5 \mathrm{~mL}$ of isopropanol. An ultrasonic bath sonicated the solution to obtain a uniform dispersion. Successively, we deposited the dispersion on a clean glass support $(117 \times 33 \mathrm{~mm})$. We let the solvent evaporate and we repeated the deposition step two more times.

All coated glass supports were then stored in a sealed, dry, and dark environment for a maximum of $48 \mathrm{~h}$ before tests.

The reactor is a cylindrical glass reactor (20 L capacity) with an LED lamp (MW mean well, $350 \mathrm{~mA}, 9-48 \mathrm{~V} 16.8 \mathrm{~W}$, emission range: $400-700 \mathrm{~nm}$ ) placed on top at a distance so that the intensity of the radiation on the sample is equal to 1000 lux. A stirring bar homogenized the composition inside the reactor. Chemiluminescence (AC32-ENVEA, Verano Brianza, Italy) measured NOx concentration. Each test lasted $3 \mathrm{~h}$.

\section{Conclusions}

We synthesized a series of metallic bismuth-doped bismuth oxyhalides and varied the chloride source to tune surface $\mathrm{Cl}$ species content. Our synthesis produced pristine compounds whose morphology depends on the chloride source. In particular, trimethylammonium salts favor flowerlike aggregates, whereas the more sterically hindered pyridinium salt CPC leads to sheet-like morphologies when coupled with amounts of added $\mathrm{NaBH}_{4}$ higher than 1 eq. XRD and HRTEM confirmed the structure of the samples. XPS analyses individuated a correlation between the metallic Bi content on the catalyst's surface with the final conversion of NOx, and we individuated this trend for the first time in a gas phase reaction. The highest performing photocatalyst among the series is the one prepared using $\mathrm{CPC}$ as the chloride source and 0.85 eq. of added $\mathrm{NaBH}_{4}$, which produced a remarkable $53 \%$ conversion of NOx after $3 \mathrm{~h}$ of visible light irradiation. This active sample is composed of crystalline nanoparticles, which feature a flowerlike morphology. The mechanism of action for this catalyst is still unclear for the oxidation of NOx and it will be the object of future works.

Supplementary Materials: The following are available online at https:/ / www.mdpi.com/2073-434 4/11/1/81/s1, Figure S1: XRPD pattern of sample 1, Figure S2: XRPD pattern of sample 2, Figure S3: XRPD pattern of sample 3, Figure S4: XRPD pattern of sample 4, Figure S5: XRPD pattern of sample 5, Figure S6: XRPD pattern of sample 6, Figure S7: XRPD pattern of sample 7, Figure S8: XRPD pattern of sample 8, Figure S9: DRS spectra of samples 1-8, Figure S10: $(A h v)^{1 / 2}$ vs photoenergy for samples 1-8, Figure S11: TEM-HRTEM images of sample 5.

Author Contributions: Conceptualization, F.T. and C.L.B.; Investigation, F.T., F.G., A.D.M., F.D., G.C.; Writing-original draft, F.T. and F.G.; Writing-review and editing, F.T., F.G., D.S., D.C.B., A.D.M., F.D., G.C. and C.L.B. All authors have read and agreed to the published version of the manuscript.

Funding: This research received no external funding.

Institutional Review Board Statement: Not applicable.

Informed Consent Statement: Not applicable.

Data Availability Statement: The data presented in this study are available in article and Supplementary Materials.

Conflicts of Interest: The authors declare no conflict of interest.

\section{References}

1. World Health Organization. Ambient Air Pollution: A Global Assessment of Exposure and Burden of Disease; WHO: Geneva, Switzerland, 2016.

2. Schwarzenbach, R.P.; Egli, T.; Hofstetter, T.; von Gunten, U.; Wehrli, B. Global Water Pollution and Human Health. Annu. Rev. Environ. Res. 2010, 35, 109. [CrossRef]

3. Stevens, G.; Mascarenhas, M.; Mathers, C. Global health risks: Progress and challenges. Bull. World Health Organ. $2009,87,646$. [CrossRef] 
4. Elfiad, A.; Boffito, D.C.; Khemassia, S.; Galli, F.; Chegrouche, S.; Meddour-Boukhobza, L. Eco-friendly synthesis from industrial wastewater of $\mathrm{Fe}$ and $\mathrm{Cu}$ nanoparticles over $\mathrm{NaX}$ zeolite and activity in 4-nitrophenol reduction. Can. J. Chem. Eng. 2018, 96, 1566. [CrossRef]

5. Bianchi, C.L.; Pirola, C.; Galli, F.; Vitali, S.; Minguzzi, A.; Stucchi, M.; Manenti, F.; Capucci, V. NO degradation in a continuous large-scale reactor using full-size industrial photocatalytic tiles. Catal. Sci. Technol. 2016, 6, 2261. [CrossRef]

6. Galli, F.; Compagnoni, M.; Vitali, D.; Pirola, C.; Bianchi, C.L.; Villa, A.; Prati, L.; Rossetti, I. CO 2 photoreduction at high pressure to both gas and liquid products over titanium dioxide. Appl. Catal. B Environ. 2017, 200, 386. [CrossRef]

7. Pirola, C.; Boffito, D.C.; Vitali, S.; Bianchi, C.L. Photocatalytic coatings for building industry: Study of 1 year of activity in the NO x degradation. J. Coat. Technol. Res. 2012, 9, 453. [CrossRef]

8. Ostad, M.I.; Shahrak, M.N.; Galli, F. Photocatalytic carbon dioxide reduction to methanol catalyzed by $\mathrm{ZnO}, \mathrm{Pt}, \mathrm{Au}$, and Cu nanoparticles decorated zeolitic imidazolate framework-8. J. CO2 Util. 2020, 101373. [CrossRef]

9. Stucchi, M.; Galli, F.; Bianchi, C.L.; Pirola, C.; Boffito, D.C.; Biasioli, F.; Capucci, V. Simultaneous photodegradation of VOC mixture by $\mathrm{TiO}_{2}$ powders. Chemosphere 2018, 193, 198. [CrossRef] [PubMed]

10. Das, A.; Patra, M.; Wary, R.R.; Gupta, P.; Nair, R.G. Photocatalytic performance analysis of Degussa P25 under various laboratory conditions. IOP Conf. Ser. Mater. Sci. Eng. 2018, 377, 012101. [CrossRef]

11. Ragaini, V.; Selli, E.; Bianchi, C.L.; Pirola, C. Sono-photocatalytic degradation of 2-chlorophenol in water: Kinetic and energetic comparison with other techniques. Ultrason. Sonochem. 2001, 8, 251. [CrossRef]

12. Bianchi, C.L.; Pirola, C.; Galli, F.; Cerrato, G.; Morandi, S.; Capucci, V. Pigmentary $\mathrm{TiO}_{2}$ : A challenge for its use as photocatalyst in NOx air purification. Chem. Eng. J. 2015, 261,76. [CrossRef]

13. Sayes, C.M.; Wahi, R.; Kurian, P.A.; Liu, Y.; West, J.L.; Ausman, K.D.; Warheit, D.B.; Colvin, V.L. Correlating Nanoscale Titania Structure with Toxicity: A Cytotoxicity and Inflammatory Response Study with Human Dermal Fibroblasts and Human Lung Epithelial Cells. Toxicol. Sci. 2006, 92, 174. [CrossRef] [PubMed]

14. Bianchi, C.L.; Pirola, C.; Galli, F.; Stucchi, M.; Mofrandi, S.; Cerrato, G.; Capucci, V. Nano and micro-TiO 2 for the photodegradation of ethanol: Experimental data and kinetic modelling. RSC Adv. 2015, 5, 53419. [CrossRef]

15. Linsebigler, A.L.; Lu, G.; Yates, J.T. Photocatalysis on $\mathrm{TiO}_{2}$ Surfaces: Principles, Mechanisms, and Selected Results. Chem. Rev. 1995, 95, 735. [CrossRef]

16. Schieppati, D.; Galli, F.; Peyot, M.L.; Yargeau, V.; Bianchi, C.L.; Boffito, D.C. An ultrasound-assisted photocatalytic treatment to remove an herbicidal pollutant from wastewaters. Ultrason. Sonochem. 2019, 54, 302. [CrossRef] [PubMed]

17. Wang, W.; Huang, F.; Lin, X. xBiOI-(1-x)BiOCl as efficient visible-light-driven photocatalysts. Scr. Mater. 2007, 56, 669. [CrossRef]

18. Zhang, K.; Liu, C.; Huang, F.; Zheng, C.; Wang, W. Study of the electronic structure and photocatalytic activity of the BiOCl photocatalyst. Appl. Catal. B Environ. 2006, 68, 125. [CrossRef]

19. Wang, W.; Huang, F.; Lin, X.; Yang, J. Visible-light-responsive photocatalysts xBiOBr-(1-x)BiOI. Catal. Commun. 2008, 9, 8. [CrossRef]

20. Shenawi-Khalil, S.; Uvarov, V.; Kritsman, Y.; Menes, E.; Popov, I.; Sasson, Y. A new family of BiO(ClxBr1-x) visible light sensitive photocatalysts. Catal. Commun. 2011, 12, 1136. [CrossRef]

21. Gnayem, H.; Sasson, Y. Hierarchical nanostructured 3D flowerlike BiOClxBr1-x semiconductors with exceptional visible light photocatalytic activity. ACS Catal. 2013, 3, 186. [CrossRef]

22. Gnayem, H.; Sasson, Y. Nanostructured 3D Sunflower-like Bismuth Doped $\mathrm{BiOCl}_{\mathrm{x}} \mathrm{Br}_{1-\mathrm{x}}$ Solid Solutions with Enhanced Visible Light Photocatalytic Activity as a Remarkably Efficient Technology for Water Purification. J. Phys. Chem. C 2015, $119,19201$. [CrossRef]

23. Dandapat, A.; Horovitz, I.; Gnayem, H.; Sasson, Y.; Avisar, D.; Luxbacher, T.; Mamane, H. Solar Photocatalytic Degradation of Trace Organic Pollutants in Water by Bi(0)-Doped Bismuth Oxyhalide Thin Films. ACS Omega 2018, 3, 10858. [CrossRef] [PubMed]

24. World Health Organization. Ambient (Outdoor) Air Pollution; WHO: Geneva, Switzerland, 2018.

25. Dong, F.; Xiong, T.; Sun, Y.; Zhao, Z.; Zhou, Y.; Feng, X.; Wu, Z. A semimetal bismuth element as a direct plasmonic photocatalyst. Chem. Commun. 2014, 50, 10386. [CrossRef] [PubMed]

26. Li, X.; Sun, Y.; Xiong, T.; Jiang, G.; Zhang, Y.; Wu, Z.; Dong, F. Activation of amorphous bismuth oxide via plasmonic Bi metal for efficient visible-light photocatalysis. J. Catal. 2017, 352, 102. [CrossRef]

27. Zhang, W.; Zhang, Q.; Dong, F. Visible-light photocatalytic removal of $\mathrm{NO}$ in air over BiOX (X= Cl, Br, I) single-crystal nanoplates prepared at room temperature. Ind. Eng. Chem. Res. 2013, 52, 6740. [CrossRef]

28. Jacob, D.J. Introduction to Atmospheric Chemistry; Princeton University Press: Princeton, NJ, USA, 1999.

29. Li, W.; Xu, Y.; Dong, Y.; Wu, Y.; Zhang, C.; Zhou, M.; Fu, Q.; Wu, M.; Lei, Y. Bismuth oxychloride nanoflake assemblies as a new anode for potassium ion batteries. Chem. Commun. 2019, 55, 6507. [CrossRef]

30. Yan, Y.; Yang, H.; Yi, Z.; Xian, T. $\mathrm{NaBH}_{4}$-reduction induced evolution of Bi nanoparticles from BiOCl nanoplates and construction of promising Bi@BiOCl hybrid photocatalysts. Catalysts 2019, 9, 795. [CrossRef]

31. Murphy, A.B. Band-gap determination from diffuse reflectance measurements of semiconductor films, and application to photoelectrochemical water-splitting. Sol. Energy Mater. Sol. Cells 2007, 91, 1326. [CrossRef]

32. Tauc, J. Optical properties and electronic structure of amorphous Ge and Si. Mater. Res. Bull. 1968, 3, 37. [CrossRef] 
33. Cerrato, G.; Galli, F.; Boffito, D.C.; Operti, L.; Bianchi, C.L. Correlation preparation parameters/activity for microTiO 2 decorated with SilverNPs for NOx photodegradation under LED light. Appl. Catal. B Environ. 2019, 253, 218. [CrossRef]

34. Wang, L.; Xu, K.; Cui, W.; Lv, D.; Wang, L.; Ren, L.; Xu, X.; Dong, F.; Dou, S.-X.; Hao, W.; et al. Monolayer epitaxial heterostructures for selective visible-light-driven photocatalytic NO oxidation. Adv. Func. Mater. 2019, 29, 1808084. [CrossRef]

35. Xu, M.; Wang, Y.; Geng, J.; Jing, D. Photodecomposition of $\mathrm{NOx}$ on $\mathrm{Ag} / \mathrm{TiO}_{2}$ composite catalysts in a gas phase reactor. Chem. Eng. J. 2017, 307, 181. [CrossRef] 